\title{
Mixing and Matching the Green and Gold Roads to Open Access-Take 2
}

\author{
Jean-Claude Guédon
}

Available online 7 March 2008

\begin{abstract}
Three years ago, the Gold and Green Roads to Open Access were viewed as complementary strategies, with repositories having the potential of gradually behaving more like journals, and vice versa. Since then, repositories and journals have been progressing on parallel tracks. Re-examining the situation, the reasoning suggested in 2004 appears still valid. Simultaneously, a knowledge economy has made of science a strategic resource. The developing world is essentially invited to contribute to world science with little or no regard to the development of an autonomous scientific capacity. Open Access, in this context, takes a new meaning with one objective to help development of local and autonomous scientific capacity. However, to do so, mixing and matching repositories with journals is needed. Brazil exemplifies this type of development and shows how the Green and Gold roads can mix and match. Serials Review 2008; 34:41-51.

(C) 2008 Jean-Claude Guédon. Published by Elsevier Inc. All rights reserved.
\end{abstract}

Three years later...

Back in December 2004, when the first special issue of Serials Review devoted to Open Access (OA) appeared, ${ }^{1}$ two very different attitudes dominated the field. The first one rested with the "Green Road," the self-archiving strategy to reach 100 percent Open Access; the other one was the "Gold Road," relying on Open Access journals. Since the Budapest meeting held in December 2001 that led to the Budapest Open Access Initiative (BOAI) published on February 14, 2002, these two roads have been clearly characterized. Indeed, they appear prominently in the text of BOAI. ${ }^{2}$

In the minds of most participants to the Budapest meeting six years ago, there was a general feeling that either road was helping to make progress and that both should be actively pursued to the extent possible and according to the opportunities that arose. The choice in favor of one or the other road was largely pragmatic. One chose the strategy best adapted to the possibilities of the moment and of the context. Alas, some OA supporters who favored the Green road began to adopt an increasingly disparaging tone toward the Gold road. The argument was that the two approaches were not of equal efficiency and, by virtue of this alleged difference,

Guédon is Professor, Département de Littérature Comparée, Université de Montréal, Montréal, Québec, Canada H3C 3J7; e-mail: jean.claude.guedon@umontreal.ca. supporting the Gold road amounted to wasting efforts on a not very good strategy. Even worse, it seems, working on OA journals was viewed as a loss of energy and of focus that could only result slowing down the general effort in favor of Open Access.

The point of my earlier paper in the OA issue of Serials Review was to defend the idea that the two approaches were valid both strategically and tactically; furthermore, I wanted to defend the idea that these two approaches could actually help each other by borrowing some of the salient advantages of the other. In short, far from being potentially divisive, the Gold and Green Roads appeared to me to be complementary resources that supporters of the Open Access movement could and should draw upon in order to help the general progress of Open Access. And I began to suggest some possible ways in which this goal could be achieved.

In 2004, the following points were shared by essentially all Open Access advocates:

1. Self-archiving in suitable repositories (i.e., OAI-PMH ${ }^{3}$ compliant at the very least) could provide access to many papers published in refereed journals.

2. Repositories had been only moderately successful in collecting the papers of their constituencies.

3. A mandate to deposit was a good thing and most researchers would comply without too many complaints. It would also provide access to most if not all published papers. 
4. Papers in Open Access gave an impact advantage over papers that were toll-gated in most cases.

However, a number of other points did not enjoy the same degree of consensus:

1. Mandates are good things but they require a great deal of political footwork and, therefore, are difficult to get. This fact of life should not discourage anyone, but neither should it be underestimated.

2. Working for archiving mandates does not exclude pushing other tactics and strategies in favor of Open Access. Revisiting how institutional depositories and subject-based repositories relate to each other, rather than treating these categories as competing strategies, is a positive step.

3. Helping journals transform themselves into Open Access journals is a positive step.

4. Helping create Open Access journals is also a good thing.

5. Helping "moving wall" journals to decrease the waiting time for Open Access is also a good thing, even though this is responding only to an "access increase principle" à la John Willinsky ${ }^{4}$ rather than an "Open Access" principle.

6. Exploring the possibility of mandating journals to be in Open Access, or at least "green," when they are subsidized by public money rests on the same basic principles as mandating self-archiving.

7. Open access will transform and hopefully reform scientific publishing even though it is not its goal.

8. Open Access viewed as a mode of scientific and scholarly publishing will necessarily lead to examining how the symbolic value of scientific texts is established.

9. Open Access debates will bring the power system of world science into clearer light.

Many of these issues have been debated over and over again in the last three years. Consequently, I will focus on just one facet of the whole OA question-namely the fact that the OA debate intersects the issue of political and economic power. As a result, OA will not progress without a better understanding of the dynamics at work within scientific and scholarly publishing (SSP). These dynamics, of course, are part of the wider dynamics of science and scholarship.

SSP does target a very particular tribe of humans, and that tribe is partially shielded from the rest of society as Robert K. Merton and his students have done so much to demonstrate. ${ }^{5}$ Pierre Bourdieu, albeit in a more critical mode, has reaffirmed the relative autonomy of what he calls the "scientific field" with regard to the rest of society. ${ }^{6}$ However, relative autonomy does not mean total isolation, and it does not exclude feedback mechanisms and the quest for various forms of science policies. Science and scholarship are financially supported by governments and even by private companies for reasons that are certainly not limited to, and guided by, the love of truth and disinterested knowledge. Science and scholarship more generally are the object of intense political debates in many countries because they play a strategic role that Francis Bacon expressed brutally centuries ago: scientia potentia est. ${ }^{7}$ The resistance to OA has a lot to do with the redistribution of power. Moving OA forward while either denying or neglecting that power element is simply unrealistic.

\section{Power and Open Access: First Approach}

Open Access needs to be strongly related to the complex realities of SSP. Its ramifications reach well beyond the boundaries of research laboratories and graduate seminars. They also reach well beyond the dozen or so countries that presently dominate scientific research worldwide. ${ }^{8}$ The issue is not to identify the tip of the scientific communication iceberg, so to speak, and work on it, hoping that by converting the head to OA in one way or another, the rest will simply follow. The reason is simple: If science, as an activity, includes a power system (and it obviously does), and if OA, rightly or wrongly, is viewed as a threat to this power system, resistance to OA will be fierce (and it is). Change, as a result, may come on the whole at the margins, as is often the case, rather than from the center. Some individuals at the center may help, of course. ${ }^{9}$

The simple presence of the expression "knowledge economy" in our vocabulary points to a strong power system where the mastery of strategically important knowledge is as important to the pecking order of nations and companies as the mastery of basic resources and the ownership of a strong industrial base. If some scholars have tried to distinguish "knowledge economy" from a "knowledge society," it is precisely to bring to light the power element involved in the former expression while retaining all the value that can be attached to the word "knowledge." 10

To approach this question in more concrete terms, let us look at the issue of how big science is? Addressing the size of science may look quite remote from addressing questions of power. The first question is quantitative and empirical while the second question is political and perhaps even ideological. Yet, despite these fundamental differences, interesting pathways lead from the first issue to the second.

The size of science is a hugely complex question that cannot be addressed here. ${ }^{11}$ However, a small subset of this issue can help demonstrate the ways in which science involves more than just scientific knowledge: it is the number of scientific journals in the world. In various Web forums or at conferences, ${ }^{12}$ figures of 22 24,000 periodicals with about 2,500,000 articles per year recur with some regularity. At the same time, many other estimates of the size of SSP exist and they vary widely.

Michael Mabe's estimate of fewer than 15,000 scientific titles in the world is the lowest. ${ }^{13}$ Much higher figures have also been advanced by credible authors. For example, nearly ten years ago, Jack Meadows gave a number of 71,000 titles for $1987 \ldots .{ }^{14}$ One of the pioneers of these quantitative measurements of science was Derek J. de Solla Price. In 1963, he was estimating 
that 30,000 titles were then active (as against about 50,000 founded since the heroic times of the Philosophical Transactions in 1665). ${ }^{15} \mathrm{He}$ also saw a steady doubling of journal titles every fifteen years (i.e., about a growth rate of about 4.7 percent per year). As a result, forty-five years later, we should be faced with eight times as many journals or 240,000 titles. ${ }^{16}$ For his part, Eugene Garfield hypothesized in 1979 that a suitably cleaned-up list of scientific journals might include about 10,000 titles. ${ }^{17}$ Using Michael Mabe's article again, we find that between 1979 and now, the growth rate of the number of titles is 3.26 percent so that, applying this figure to the base figure provided by Eugene Garfield, we should now have about 25,400 titles. Using Price's rate of growth (4.7 percent), on the other hand, would yield about 36,200 titles. In 2006, in PLoS ONE, John Ioannidis advanced the hypothesis of about 100,000 scientific titles but did not attempt to justify his figure. ${ }^{18}$

The issue, of course, is what counts as a scientific or scholarly journal. Most of the authors cited above make this point. For example, in Latin America, Latindex covers 16,200 journals of "academic interest" from Latin America. Such a figure will not sit easily with Michael Mabe's calculation except if the qualification "of academic interest" is - from Mabe's perspective read as a very relaxed set of conditions imposed upon scientific journals. The point here is not to estimate the number of scientific journals in the world but simply to show that such a number is difficult to pin down. Several reasons explain why results vary widely. For example, many calculations rest on Ulrich's Periodicals Directory, ${ }^{19}$ and those tend to yield lower numbers; on the other hand, higher numbers emerge when researchers try to estimate the number of scholarly and scientific journals through more direct methods. It is not that Ulrich's does its work badly, but it aims at a specific clientele largely made up of librarians from rich countries. $^{20}$ It selects what it thinks is of potential interest for potential buyers. Its "universe," to use Ulrich's own vocabulary, covers 270,000 titles, out of which the company identifies a "core" of 70,000 "active titles representing academic and scholarly journals and major consumer and trade publications." 21

Rather than ascertain the accuracy of one number against another, it is more useful to examine the import of choosing smaller against larger numbers. Several factors can explain the interest in smaller numbers. For example, as I argued several years ago, ${ }^{22}$ the design of the Science Citation Index involved using Bradford's law of scattering which, read backward, led to the identification of a core set of journal titles for each scientific specialty. From there, it was only a small (but questionable) step to define the union of these small core sets as the set of "core journals." One might ask: What core? Does science exhibit a core? And, if so, what is its nature? What does it mean?

With a good deal of pragmatism, Eugene Garfield bypassed these questions, went ahead and performed the union of all the small, specialty-based, core sets. This helped him truncate the number of journals to a level sufficiently low to track article citations with the computer possibilities of the late sixties and early seventies, and to justify this "move." If the total number of journal titles is given as smaller rather than greater, the truncating process appears less extreme and consequently easier to accept. Garfield's construction of a truncated list of "core journals" ultimately contributed to the transformation of the publishing structure of science: The Science Citation Index excluded most journal titles. It also provided a ready list of "must-buy titles" for librarians, with obvious market consequences. In fact, $S C I$ titles became part of an inelastic market and the rest is part of the so-called "serials pricing crisis" history.

Not surprisingly, the limits of the SCI set of journals attracted some critical attention. The procedures and criteria used to select journals have been scrutinized and criticized, in particular from the perspective of developing nations. Most famously, an article published in Scientific American in 1995 raised some important questions. In it, the testimony of Mexican scientists involved with the publication, Archivos de Investigación Médica, seemed to show that the quest to identify core journals and to demonstrate their excellence could also involve financial considerations:

Of course, there were conditions: to remain in the SCI, Archivos had to publish its issues on time, provide English abstracts for its Spanish articles-and purchase a $\$ 10,000$ subscription to the index. All of which the journal did, until 1982. "But then the country went through a terrible economic crisis, resulting in a delay of publication for six months," Benítez recalls. Although the editors explained the situation to ISI and pleaded with its managers for patience, "they couldn't care less," he says. "We were out of the database." 23

Indeed, $S C I$ has been criticized for being biased against developing nations or peripheral countries. The term "bias" will undoubtedly raise some eyebrows, but it can nevertheless be substantiated in a variety of ways. For example, in 1982, a meeting was held at the Institute for Scientific Information (ISI), the home of SCI, where the issue of the presence, representation and impact of "peripheral" or "Third-World" countries was debated. One of the participants, D.J. Frame, expressed SCI's viewpoint rather clearly:

If the purpose of the bibliometric indicators is to help in the building of a national scientific inventory, telling us what kind of research is being performed at different institutions, then coverage of local as well as mainstream publications would seem important. On the other hand, if one is primarily interested in investigating Third World contributions to world science, then publication counts taken from a restrictive journal set would seem most appropriate. ${ }^{24}$

Frame's contrast between "World science" and a national "scientific inventory" in effect reiterates Garfield's contention that only "core journals" really count in science. "National publications" from developing nations are simply not interesting in this perspective. 
If being included into $S C I$ is important, it is important to know why. Is it to be part of a useful and innovative bibliographic tool or is it to join an elite club of core journals? What is at stake is obviously more than visibility and making information retrievable; it also relates to the prestige of belonging to a select group. SCI locates valuable information in a "select" or "exclusive" group of journals, as one would say of an exclusive social organization. Moreover, SCI has managed to place itself in the enviable position of deciding who can join the club. Finally, through the impact factor, SCI has organized a measuring stick that everybody (mis)uses, from the ranking of journals - its original function - to the evaluation of individuals, institutions and even countries. In the end, what initially appeared as an exercise aiming at the identification of "excellence" in an objective manner turns out to describe a selection process defining an elite and allowing its members to identify each other while they sit at various levels of the scientific totem pole (in this case measured by ISI's Journal Citation Reports). The exercise becomes even more suspect if we turn to the conclusion of a recent study on the factors contributing to citations:

We found that the impact factor of the original publishing journal, not the methodology or quality of the research, was the strongest predictor of citations per year... Citation may be more strongly influenced by the reputation of the publishing journal than by the design merits of the study. Thus, a strong or seminal paper submitted to a minor journal might not receive the scientific recognition it deserves. Likewise, a weak article published in a major journal will probably receive more recognition than it deserves. ${ }^{25}$

The set of "core journals," it appears, is a construct. The nature of such constructs is complex because it must appear objective to remain credible, but it also helps create a form of elitism. Small numbers of titles then begin to make more sense because they introduce an element of scarcity without which value, either monetary or symbolic, cannot be established. SCI's choice of titles appears equally suspicious when examined from a national perspective; for example, in 1987, when Garfield's brainchild covered around 3,000 titles, only ten of them were from India. Yet, the year before, BIOSIS, while covering 9242 titles, included 273 journals published in India. ${ }^{26}$ Another international bibliography, Chemical Abstracts, covered 288 Indian titles. ${ }^{27}$ If such international and reputable bibliographies indexed so many more titles from India than did SCI - and similar results could be documented for the majority of countries in the world - surely SCI's approach to title selection deserved some questioning. It still does.

Undoubtedly, rationales can be (and have been) ${ }^{28}$ adduced to bolster SCI's choices, but the degree to which they are arbitrary is quite easy to demonstrate: The list keeps expanding. The number of journals retained by $S C I$ has grown considerably over time to reach around 8,000 titles nowadays. If the truncation was so good in the past, why move so much beyond the original thousand or so titles that were used in the early years of the SCI. Perhaps SCI's real role is not so much to identify excellence (although it does identify excellent journals) as to keep the hoi polloi outside its gates. However, as the pressure from more journals to be included increases, $S C I$, it appears, gradually relaxes its own principles.

It will be interesting to observe how $S C I$ evolves its list of titles while confronting the competition from other indexing systems such as Elsevier's Scopus. The recent decision by the Times Higher Education SupplementQuacquarelli-Symonds (THES-QS) ranking of world universities to shift from the Essential Science Indicators (ESI) derived from the Web of Science to Scopus may well mark the beginning of this new form of pressure on the SCI list of titles: Scopus presently covers about 15,000 titles and conference proceedings, or about twice as many as the Web of Science. ${ }^{29}$

To conclude this part of the paper, the issue of counting the number of scientific journals is not as neutral and objective as it may seem. It actually translates into arguments to justify the design and limits of tools such as SCI or Scopus; it can also strongly influence the behavior of a number of institutions and actors ranging from libraries in their procurement strategies to authors in the management of their careers. In short, these tools contribute to the structuring of various markets, some monetary (procurement of journals for libraries) and some symbolic (individuals, programs, and institutions passing muster in front of various kinds of juries, including various national assessment exercises). From the very beginning, they have been on the radar screens of commercial publishers: Robert Maxwell tried to acquire SCI from Eugene Garfield for years and even sued him to try forcing his hand. In so doing, Maxwell clearly showed that he had fully understood how much power there was in defining the size and contours of significant scientific publications. ${ }^{30}$

\section{Power and Open Access: Second Approach}

The Republic of Science emerged among gentlemen, and it never quite forgot its origins. Its Republican, egalitarian ethos was applied only to those who managed to be included into its ranks. Within the boundaries of the Republic, all were peers, but the competitive nature of this peculiar social structure gave to "equality" only its limited sense of "equality of opportunities." Various factors such as native intelligence, but also access to human and material resources, rapidly allowed various degrees of inequality to reaffirm themselves. At the same time, the gentlemanly context within which this Republic built itself generated a culture of "noblesse oblige": it would not be difficult to show how this form of studied generosity was able to transform itself into what has sometimes been described as a gift economy. ${ }^{31}$

Behind the elegance of the pose and the foregrounded geniality of the Republican spirit lies an elitist foundation that remains essential to the understanding of a good deal of the dynamics of science and scientists. Much 
closer to us, the scientific sphere has reinforced its "equality of opportunities" facade by providing entry points to new members through schools and diplomas. As a result, science did manage to open itself not only to the ever widening circles of citizens coming from many walks of life, but particularly to the middle and professional classes. If science did not always manage to avoid all controversies with various churches, its professed distance from theological matters and its admission that it had nothing to say about metaphysical questions or matters of faith gave it an ecumenical turn that completed its basic "Republican" spirit. In short, science became one of the favorite ways in which (mainly) men could hope to move up in society by joining a cultural subset that incorporated some of the values of the noble elite while justifying its existence by giving back to the State (through its academies and societies) a number of results and technical applications deemed useful for the economic life of the nation or for its military power. Limited at first to those who could find the time and resources to carry on the research or observations needed to mark one's spot in the Republic of Science, it ultimately linked up with the professional ethos to create the figure of the modern scientist.

Given this genealogy of science (in Michel Foucault's meaning of the word), no one should be surprised by the strong presence of power motives at the heart of its dynamics; yet, in a rather fascinating manner, science has constantly managed to belittle and even deny the power factor in its midst. For a long time, for example, the history of science was portrayed as the history of (pure) scientific ideas-iter mentis ad veritatem was the way Alexandre Koyré, the great historian of science, put it. One may note in passing that his expository style, all the way to his use of Latin, agreed perfectly with his thesis. When power was mentioned in that kind of history, it took on the trappings of political or religious power, and it was generally depicted as an exogenous factor that could only act negatively on science: the Church and Galileo, the Nazis and Einstein, the Communists, and Andrei Sakharov have been regularly brought to the bar to testify to the fact that interfering with science could only slow down its progress but could not stop human reason on its heroic path toward truth: iter mentis ... all over again.

In looking at the ways in which science works today, it is difficult not to notice the modern equivalent of these myths. One quick example will make the point clear. Science is often described as "universal." Strictly speaking, this claim simply means that a result found somewhere on the earth should be applicable any place else, in fact in the whole universe. When humanity subscribed to Newton's theory of universal gravitation, it simply obtained everywhere. The transformation of this theory by Einstein is just as universal. However, although the results of science apply equally well everywhere, access to what is needed to practice science is not so well distributed. In particular, access to the scientific literature is extremely uneven. In short, while science is truly universal at the epistemological level, its globalization reveals deep inequalities and strong patterns of domination.

Documenting the many facets of uneven access to science is not the point of this paper, but some obvious details as well as a few less obvious points can be quickly presented here:

- Anyone doing research will find references to texts that remain inaccessible or difficult to access simply because the local library does not own the book or subscribe to the journal where this piece of information can be found. Extend this to whole countries and make it the rule rather than the exception and you have essentially described the situation in poorer countries. Again, science may be universal in its applications, but it is not globally accessible to all concerned;

- The creation of tools like general disciplinary bibliographies automatically raises the issue of boundaries, as we have seen in the case of the SCI. No bibliography can pretend to include everything and most, quite consciously or methodologically, prefer to put bounds on their effort both for the sake of the people in charge (and the costs involved) and also to give the reader the feeling that some form of basic selection has been at work separating the wheat from the chaff. The results, as we have seen earlier, tend to respond to the scientific productions of a limited number of countries, as well the needs of their scientists. Publications from the rest of the world are overlooked, neglected or devalued;

- Scientists who are not part of the inner circle of scientifically dominant countries do not really belong to the Republic of Science, but only to some of its border areas at best. This means that, to be recognized internationally - what D.J. Frame coyly called "contributing to world science" 32 - such scientists must fit within the research agendas of the dominant countries as defined by the editorial policies of so-called "mainstream journals." In passing, this displays a curious form of foreign aid in reverse: the scientist from a poor country must help solve problems dictated by scientific communities in rich countries and devote rare resources to solve questions that may be of very little practical relevance in the country where he/she works. ${ }^{33}$ Thus are "orphan diseases" created, as they are sometimes called. ${ }^{34}$ The governments of the poor countries simply do not have the means (and/or the will) to undertake this effort. ${ }^{35}$ The net result is that the few practicing find it very difficult to develop an autonomous capacity and ultimately the very notion of autonomous scientific capacity appears to collide with the principle of universality.

- If the better scientists of a poor country send their best papers to international journals in order to maximize their visibility, is it surprising to discover that local journals do not attract many high quality articles? ${ }^{36}$

- Studies focusing on the gatekeepers associated with scientific journals reveal further biases. For example, according to Tibor Braun and his collaborators, the number of gatekeepers from developing nations is 
negligible in the top core journals of twelve scientific fields. ${ }^{37}$ On the other hand, " $75 \%$ of the positions of power influencing the publication of new results in almost all areas of science are concentrated in the hands of scientists from no more than ten countries in the world." Add to this result the point that "a correlation has been shown to exist between the number of gatekeepers of a given nationality and the number of papers published in these journals by scientists of the country concerned" 38 and a picture begins to emerge which can be diversely described as a "Matthew Effect for Countries" 39 if viewed from one of the countries benefiting from this situation, or as "learning to communicate science" if you live in Brazil. ${ }^{40}$

- Finally, linguistic barriers do create an added handicap for non-native speakers of English.

In conclusion, the highly skewed distributions routinely observed in various parameters used to describe scientific publishing are not only repeatedly confirmed but they lend themselves readily to the interpretation that a power system is present in the heart of the various scientific communities. This power system does not simply regulate hierarchic relations between individuals but also between institutions and countries. The same structures reappear on different scales of scientific operations, thus lending to the structure of science some of the characteristics of fractals in mathematics. At the same time, these qualities of scientific communication help us to understand how power works in science all the way to the international level. Curiously, Eugene Garfield expressed all this very well with a delightful lapsus calami: "Western journals control the flow of international scientific communication almost as much as Western news agencies monopolize international news." "Garfield probably meant to say "dominate" rather than "control," but the word "control" did emerge as if the reality of power in science managed to find its way to the surface and thus reveal the presence of a knowledge economy behind the genteel trappings of the Republic of Science. In such a context, the flow of knowledge understandably must follow well-secured communication paths just as the flow of oil or natural gas must run through well-protected pipelines.

\section{Positioning Open Access in Science and Science in Society}

Most of the arguments presented in favor of Open Access have been couched in terms of advantages for researchers, particularly researchers in leading institutions. The OA advantage is debated on the basis of citations not being wasted and even economic value has been placed on this manque à gagner ${ }^{42}$ : A research grant gives rise to a number of papers that, in turn, generate citations. Dividing the latter number into the initial sum of money gives an average cost for each citation. When OA brings about a surplus of citations, its value can be calculated by simply multiplying the number of extra citations by the unitary cost of a citation. It all looks very quantitative and therefore rhetorically effective, at least in some circles. Is it the best argument one can bring to defend $\mathrm{OA}$ ? Hopefully, this is not the case.

A somewhat better argument rests on the analysis of scientific communication as a process within a gift economy: If, as a scholar or scientist, I publish results with the intention of sharing freely these results with my peers but a third party locks up the access to my "gifts," something is awry. The usual answer to this objection is that libraries are there to correct this anomaly resulting from the economic gains of publishers. Libraries in effect subsidize each reader and thus nullify the negative consequences of the publishers' presence. Publishers argue over and over again that their presence is indispensable because they add value to the texts that authors provide (and most often do give away). ${ }^{43} \mathrm{Be}$ as it may, this complicated solution to a simple communication problem does raise some issues that libraries cannot always solve. For example, in developing nations, libraries either do not exist or do not have the means to subsidize the reader. In this case, our colleagues cannot benefit from our gifts at all. Furthermore, the library subsidy designed to compensate for the commercial requirements of the publisher necessarily target certain groups of people and as is always the case in this kind of exercise; the targeting can lack precision. As a faculty member of a reasonably financed university, I am subsidized to read all kinds of documents I will never need or cannot use because of personal limitations or lack of interest. I can consult journals dealing with mathematical topics that I cannot even begin to decipher, but mathematicians down the road in a poorer institution may not be able to access these journals. I can look at specialized publications on very technical elements of ophthalmology, but an ophthalmologist not connected with a university hospital may find it much more difficult, time consuming, and costlier to access the same journals although they would be far more useful to him/her than to me.

In short, the library subsidy system does not work very well, especially when we consider the matching of needs with provisions. Furthermore, the very nature of our institutions leads them to buy access rights to journals for the whole campus although they may serve only a very small fraction of the university community: Many licenses providing access to journals are negotiated on the basis of the population of the whole campus, with perhaps some consideration for the size of the graduate school or the departments most interested by certain titles. However, when licenses are negotiated for hundreds of titles, especially in the case of so-called "big deals," the deal is discussed as if everybody were a potential reader of everything included in the deal.

At the same time, the same journals are not available to many people who could make good use of at least some of them. For example, in the humanities and the social sciences, a majority of the articles can be read without any difficulty by school teachers or even informed citizens. Given the many social problems we encounter in our societies, it would seem useful to let citizens access the best information possible on issues of 
intercultural dialog, integration of recent immigrants, treatment of minorities of all kinds, etc. Given that nearly all these articles have been made possible by public support in one form or another and given that they have been given away by their authors, it becomes clear that the library subsidy as correction for the publishers' business plan is inadequate.

Another important consequence stems from this situation: The toll gating of scholarly and scientific publications essentially guarantees that research results will flow only from researchers to some researchers (and not always the right ones, as was pointed out earlier). In so doing, however, these documents take on a very peculiar life form: By circulating only within the limits of academe and similar research sites, scientific publishing becomes esoteric, almost secret. It certainly contributes strongly to the ivory tower syndrome. Even the literature that could be used profitably by significant fractions of the population remains out of reach and largely invisible. Literature journals that could interest tens of thousands of high school teachers may be distributed in runs of a few hundred copies. Opening up such journals to the public in general may not provide much OA advantage if it is measured in citations exclusively, but it would certainly bring a measure of good will toward universities that could and would accept to satisfy the intellectual and teaching needs of countless high schools and even below.

In some disciplines some of the time, it would shift the demographic characteristics of readers. As a result, the very meaning of the knowledge produced would change: Rather than just being a dialog between "specialists," it would also incorporate the reactions and inputs of much wider circles of readers. It would bring that knowledge closer to the general population, and it would contribute to making these forms of research less elitist. Of course, it may well be on this very point that such suggestions will be most strenuously resisted: As we have seen earlier, creating and maintaining an elitist system is a project that seems generally to attract a significant fraction of individuals. Obviously, they hope to be part of, and recognized as, VIP's to use the vocabulary of airport lounges. More seriously, however, the many critiques leveled at the esoteric and largely irrelevant nature of much university knowledge would probably tend to decrease if the research results emanating from universities and research centers were simply available in Open Access to anyone.

The point here is not to rely on some communication utopia that, by virtue of simply existing, would solve all social ills. It is more to redress the feeling of alienation that segments of the population may feel with regard to universities simply because they have no opportunity to examine what goes on in those institutions. If the universities are public universities and the alienated individual are frustrated tax payers, the recipe for potential disasters is evident.

The conclusion of this part is now easy to express: The present system of scientific and scholarly communication is inefficient and generates many problems, and the means used to correct these flaws are both in- effective and costly. Putting the results of scholarly and scientific research in Open Access brings to the scientific and the scholarly system of communication a greater degree of coherence. There is no doubt that it would help the researchers and scholars in their attempts to communicate with one another and build "on the shoulders of giants" as the famous saying goes. But it would also open up the flow of knowledge in new areas of society at a time when many events seem to point in the direction of great need for such knowledge: The extraordinary social and intellectual energy mobilized by the Wikipedia project appears proof enough of this claim. And in opening up the barriers that presently limit the dissemination of research results wherever and whenever they may be needed, knowledge itself would root itself differently in the social body: specialists would not speak only to specialists; they would also face members of the public endowed with varying degrees of training and intelligence and the results could be quite transformative.

\section{Next Steps: How to Mix and Match the Green and Gold Roads}

Having reached the issue of strategic planning, it is useful to underscore once more what has been an underlying argument of this whole paper: Against the simplistic assumption that reaching OA is a simple matter of depositories, mandates, and a few keystrokes, the present paper tries on the contrary to see how Open Access can work within science and how this may affect the position, the functions, and the perceptions of science and scholarship in society at large. The context of scientific and scholarly activities has been presented as constructed by a series of tools such as SCI that incorporate various degrees of arbitrariness in their design and that relentlessly seek to create levers to regulate a highly competitive Republic of Science and its symbolic currencies. One of the consequences of this general system is that it effectively (and efficiently) cuts out the vast majority of humanity, thus ensuring that the benefits of the knowledge economy accrue to a minority of rich countries.

Treating Open Access as purely a researcher-toresearcher issue and as providing an advantage to the same researchers is much too narrow an approach. It is too narrow despite the fact that it will, nonetheless, achieve some of the repositioning effects discussed earlier. However, in not mentioning such effects, many potential alliances are missed or made far more difficult. For example, a good deal of the efforts to pass a law mandating the deposit of publicly supported research in the United States was based on the Alliance for Taxpayer Access. ${ }^{44}$ This was a very important move not only for tactical reasons, but also because it demonstrated that medical research could be of great interest to more than health specialists. Patients in particular deserve the best access to the medical literature that may be relevant for their particular situation. Yet, despite general agreement and support 
for this development, Stevan Harnad reacted with statements such as the following:

\begin{abstract}
But let us not forget that most research is highly specialized and often technical, and written for the use of other specialized researchers. This of course does not mean that it should not all be openly accessible to the general public as well! But the benefits - to the tax-payer of making that research open access go far, far beyond the benefits from the tax-payer's being able to consult it directly:
\end{abstract}

For the reason the tax-payer funds research is in order to generate research progress. Most research doesn't turn into something that can be applied and used for public benefit immediately after it is done and reported! Research progress is cumulative and collaborative, and often slow, and it is "researchers" who most need immediate access to one another's output. It is the taxpayer who benefits if researchers do have this access to one another's research output, and the tax-payer (and research progress itself) that loses if researchers do not have that access to one another's research output. ${ }^{45}$

In reiterating the primacy of the researcher, in insisting on the separation of scientific research results from the concerns of even an informed and interested public, Stevan Harnad tries to make his peculiar form of elitism converge with Open Access. Not surprisingly, this leads him into convoluted thinking. It is also interesting to note that he spontaneously assumes that the general public is interested only in applications and direct benefits, and not in knowledge per se. In the end, researchers are represented as wanting access first and foremost. However, if all researchers were adequately subsidized as readers, what role would be left for Open Access in Harnad's vision? And an adequate increase of the subsidies of the readers in the form of greater budgets for libraries is precisely what publishers have been advocating all along. This is not surprising as it would increase their revenue stream considerably, as well as respond to the need for access among researchers which Harnad places as the center of gravity of his position.

Obviously, more is needed to achieve Open Access, and it is not by chance, serendipity, or opportunism that groups external to the research world find themselves involved in the battles in favor of Open Access. As a result, we must revisit the tactics used to achieve Open Access, which brings us back to the "mixing" and "matching" of ways. A good way to examine anew this situation is by examining one concrete example and draw some lessons from it. This example is the SciELO program, which covers now a large part of Latin America and extends into Europe. ${ }^{46}$ What SciELO does is to take seriously the need to generate scientific activities that will truly take roots and allow for the autonomous development of a scientific capacity. To do so, some coherence had to be applied to governmental subsidy programs that already existed but failed to help the development of science in Brazil and elsewhere. The financial support of journals committed to a subscription model increasingly appeared as contradictory so that, a few years back, the leaders of the project decided to bite the bullet and go into full Open Access. They did so with one extra step in that they accepted the idea of being subsidized and then decided to remove all barriers also at the point of entry: No fees are required to publish in SciELO. This does not prevent looking for ways to make the whole structure financially more robust by finding other forms of financing, but the primary objective was to build a system of electronic journals that would have a chance of being used internationally by being in Open Access, and of attracting good authors by offering peer review and Web publishing for free.

The next stage was to build a sufficiently important collection of journals over a sufficiently long period to permit the generation of statistical results that would be interesting not only to manage the whole system, but also to evaluate the visibility of the SciELO journals independently of the SCI. In short, Brazil and her partners began to free themselves from the universal yardstick imposed on scientific publishing since the beginning of SCI. If these new measures are accepted by institutions for their career management needs (tenure and promotion, adjudication of research grants, etc.), it will be a success. If it truly becomes international and begins to join up with similar efforts, for example, the Chinese Science Citation Database, then some very important developments may well be in the offing. ${ }^{47}$ In effect, SciELO is pointing Open Access in an original direction by demonstrating that it cannot be dissociated from the means to create symbolic value and evaluation standards for the OA journals. It also clearly identifies the blockage points and suggests new ways to by-pass them. This supports the contention of this paper that Open Access must be analyzed with due respect to the whole complexity of science and its activities. However, more can be added.

If we consider each SciELO journal independently, it begins to take on a very familiar appearance. Because there is no financial barrier to publishing and because it is in Open Access, it can easily be described as a thematic or subject-based repository that has added some peerreview capacity and some Web publishing know-how. It is not surprising that SciELO has recently decided to adopt the "Open Journal System" designed by John Willinsky and his collaborators. ${ }^{48}$ Adopting OJS amounts to adding peer-review capacity to a repository. As for the publishing itself, all depends on the ambitions of the publishing institution. In the case of SciELO, XML is obviously available since SciELO provides a description of its "document type description" or DTD. But the point here is not to discuss how to do electronic publishing; rather, it is to point out that the SciELO journals behave very much like depositories that have been tweaked a little. In fact, the SciELO portal is little more than a set of thematic, journal-based, depositories plus a few more tools including the evaluation tools mentioned earlier ${ }^{49}$; however, because they are journals, they automatically include the branding capacity of scientific journals. Some of these journals are even listed in SCI and can therefore rely on the established tools, for 
example, the impact factor, for the measurement of acquired authority. But, for the majority of these journals, this is not the case, and they rely then on the metrics provided by SciELO.

The example of SciELO is all the more important that it appears to respond symmetrically to a suggestion made in my 2004 article. At that time, I had begun my reasoning from the opposite end, looking at the possibilities offered by repositories and trying to enrich them by offering a first approximation of what could be a publishing (or rather re-publishing) system of articles based on repositories. The idea was to pool articles according to subjects, then create sufficiently large collection by networking several institutional repositories and finally by organizing various evaluative activities on top of these repositories to permit the measurement of some forms of quality among these articles. Gradually, I argued then, some of these networks would acquire sufficient reputations to begin attracting papers directly. This in turn would lead to developing some peer-review process around the depositories. Perhaps, in such cases, peer review could take a form close to that of PLOS ONE, but it could also accommodate more traditional forms of peer review. The point there was not to nail down a particular form of peer review, or of symbolic value creation, but simply to show that depositories could be made to evolve in such a way as to begin to fulfill some of the functions generally associated with traditional journals.

The SciELO example is interesting because it displays journals beginning to evolve in the direction of depositories. It does demonstrate that "mixing" and "matching" is already taking place and is growing in importance in Brazil. It may grow even more in importance if a Brazilian mandate for archiving is voted into a law in the next few months. ${ }^{50}$ If this law is passed, it is probable that some coordination will take place between the depository-based archiving movement and SciELO. In other words, mixing and matching would then take place on a national basis.

\section{Conclusion}

Six years following the initial Budapest meeting, the Open Access movement has demonstrated considerable strength and can point to some important successes. The very fact that we now speak in terms of a "movement" is a testimony to the progress accomplished. The number of institutions that have signed on to the OA project is large and worldwide. No continent has been left untouched. At the same time, much remains to be done. This paper has suggested returning to a three-year-old suggestion, which was to mix and match the Green and Gold roads, but it is argued now in terms of the need to examine the power system of science much more closely and with caveats against simplistic arguments, especially when they are coupled with an elitist vision of the researcher or the scholar. The case of Brazil is, of course, a great comfort in this context because it demonstrates, in effect, that Open Access is reachable simply if governments follow the logic of supporting research to its end: Publishing is an integral part of research. Its financing should be included in the costs of research. Furthermore, compared to the cost of research, it is very low, of the order of 1 to 2 percent at most. Already, SciELO demonstrates spectacular results with relatively small sums of money: In 2005, with one million US\$, SciELO managed to put about 160 journals in full Open Access. The same year, with about US $\$ 2.5$ million, Canada and Quebec, together, supported about the same number of journals, all in the social sciences and in the humanities, and they could not find a way to wean these journals from a subscription model.

Brazil therefore harbors a model that, by its efficiency and its coherence, has become the inspiration for about nine other countries in the region. It may soon attract the attention of the whole world and will thus demonstrate that Open Access can indeed help the development of autonomous scientific capacity.

\section{Notes}

1. Serials Review, Vol. 30 No. 4 (2004). I want to thank my wife, Frances K. Groen, for having helped me write this article in legible English, and for some precious suggestions.

2. See http://www.soros.org/openaccess/read.shtml.

3. See http://www.openarchives.org/OAI/openarchivesprotocol. html.

4. John Willinsky, The Access Principle: The Case for Open Access to Research and Scholarship (Digital Libraries and Electronic Publishing) (Cambridge, MA: MIT Press, 2005).

5. See, for example, Robert K. Merton, On Social Structure and Science, ed. Piotr Sztompa (Chicago: University of Chicago Press, 1996).

6. Pierre Bourdieu, "La spécificité du champ scientifique et les conditions sociales du progrèes de la raison," Sociologie et Sociétés 7, no. 1 (1975): 91-118.

7. This famous aphorism, generally translated by "knowledge is power," is found in Meditationes Sacrae (1597).

8. One way to approach this question is to look at the national distributions of top gatekeepers in science publications. Some results have been coming out of the work conducted by Tibor Braun and his collaborators since the 1980s. See a summary of his main results in Tibor Braun, "Keeping the gates of Science Journals" in Handbook of Quantitative Science and Technology Research, Henk Moed, Wolfgang Chenzel, and Ulrich Schmoch, eds. (Dordrecht: Kluwer Academic Publishers, 2004), 95-114. On a distinct, but related, question, see Manfred Bonitz, "Ten Years [of] Matthew Effect for Countries," Scientometrics 64, no. 3 (2005): 375-79.

9. The example of Harold Varmus immediately comes to mind.

10. See Sverker Sörlin and Hebe Vessuri, "Introduction: The Democratic Deficit of Knowledge Economies," in Knowledge Society vs. Knowledge Economy (London: Palgrave MacMillan, 2007), pp. 2-32.

11. See on this Derek J. de Solla Price, Little Science, Big Science (New York, Columbia University Press, 1963).

12. See http://www.amsci-forum.amsci.org/archives/AmericanScientist-Open-Access-Forum.html.

13. Michael Mabe, "The Growth and Number of Journals," Serials Vol. 16, No 2 (July 2003), 191-7. Mabe claims that Derek de Solla Price had estimated there would be a million titles at the end of the twentieth century but this refers only to a linear 
extrapolation of a growth curve found in Derek J. de Solla Price, Little Science, Big Science (New York, Columbia University Press, 1963). Price cautiously does comments that stricter definitions of scientific publications could shift numbers by one order of magnitude, thus potentially bringing that number down to 100,000 titles.

14. Jack Meadows, Communicating Research (San Diego: Academic Press, 1998), p. 15.

15. Derek de S. Price, op. cit. (note 2), p. 8 and accompanying graph on p. 9.

16. However, to go back to Price's word of caution (see note 2), a stricter definition leading to a result one order of magnitude lower would yield the 24,000 figure often used in OA debates.

17. Eugene Garfield, Citation Indexing. Its Theory and Application in Science, Technology, and Humanities (New York, John Wiley \& Sons, 1979), 20. In January of 2004, Eugene Garfield suggested the number of scientific journals in the world would probably stand somewhere between ten and fifteen thousand titles. See http://www.users.ecs.soton.ac.uk/harnad/Hypermail/Amsci/ 3389.html.

18. John P.A. Ioannidis, "Concentration of the Most-Cited Papers in the Scientific Literature: Analysis of Journal Ecosystems”, PLOS ONE 1.1 (2006), http://www.dx.doi.org/10.1371\%2Fjournal. pone.0000005 (accessed December 13th 2007).

19. In Ulrich's is, for Michael Mabe, a condition to be a "learned journal." Mabe, op. cit. (note 13), 192.

20. Ulrich's FAQ specifies that "Ulrich's Serials Analysis System is designed for password-protected use by library professionals only, and is not a patron-interface product." See http://www.ulrichsweb. com/ulrichsweb/usasfaq.asp (accessed December 13, 2007).

21. The conflation of academic and trade journals is a little puzzling given the attachment of scientists and scholars to peer review and their desire to separate research papers from other publications as precisely and neatly as possible. Responding to this need, Open J-Gate.

22. Jean-Claude Guédon "In Oldenburg's Long Shadow: Librarians, Research Scientists, Publishers, and the Control of Scientific Publishing," http://www.arl.org/resources/pubs/mmproceedings/ 138guedon.shtml.

23. Scientific American, August 1995. The citation was pulled from the Scientific American web site at http://www.sciamdigital.com/ index.cfm? fa=Products. ViewIssuePreview \&ARTICLEID_ CHAR=082AA6E7-13D1-4610-81F4-EEC68867A24. There was a reply by the Science Citation Index in the form of a letter to the Editor of Scientific American, October 1995, p. 10. See http://www.garfield.library.upenn.edu/papers/currscience. html\#tref6.

24. D.J. Frame. "Problems in the Use of Literature-based S\&T Indicators in Developing Countries.” In: H. Morita-Lou, ed. Science and Technology Indicators for Development. (Boulder, CO: Westview, 1985). 117-22. The quotation is from The Uncertain Quest: Science, Technology, and Development (Paris, United Nations University Press, 1994), Jean-Jacques Salomon, Francisco R. Sagasti, and Céline Sachs-Jeantet and is available on-line at: http://www.unu.edu/unupress/unupbooks/uu09ue/ uu09ue $0 \mathrm{~m} . \mathrm{htm}$. According to S. Arunachalam who attended the ISI meeting, it took place in 1982 and not in 1985. Personal communication from S. Arunachalam, November 4th, 2007.

25. M. Callaham, R.I. Wears and E. Weber, "Journal Prestige, Publication Bias, and Other Characteristics Associated with Citation of Published Studies in Peer-Reviewed Journals," JAMA 287, no. 21 (June 5, 2002): 2849. Some studies disagree with this conclusion, for example, Bhandari M, Busse J, Devereaux PJ, et al., "Factors Associated with Citation Rates in the Orthopedic Literature," Canadian Journal of Surgery, Vol. 50 No. 2 (April 2007), 119-23.
26. Ironically, BIOSIS is now part of Thomson Scientific, which owns SCI.

27. S. Arunachalam and K. Manorama, "Are Citation-Based Quantitative Techniques Adequate for Measuring Science on the Periphery?” Scientometrics 15 (5-6) (1989): 394.

28. One of the more candid arguments in favor of truncating the list of journals is "cost effectiveness" as Garfield explains: "The cost-effective objective of an index is to minimize the cost per useful item identified and to maximize the probability of finding any useful item that has been published.... A cost-effective index must restrict its coverage, as nearly as possible, to only those items that people are likely to find useful.” E. Garfield, op. cit. (note 17), p. 20.

29. See http://www.topuniversities.com/worlduniversityrankings/ university_rankings_news/article/why_scopus/. In passing, the figure of 15,000 titles fits nicely with the results announced by Michael Mabe in the article cited earlier (see note 13). Although Michael Mabe was working for Elsevier when he wrote this article and Scopus is an Elsevier product, the coincidence may be just the result of some pre-established harmony.

30. Eugene Garfield briefly recounts his problems with Maxwell in an interview by Robert V. Williams in July 1997. See http://www. garfield.library.upenn.edu/papers/history/heritagey1998.html and http://www.garfield.library.upenn.edu/papers/oralhistorybywilliams. pdf.

31. See Steven Shapin, A Social History of Truth, Civility and Science in Seventeenth-Century England (Chicago: University of Chicago Press, 1995), passim.

32. See note 23 .

33. There is an even more perverse situation that has been described to me by S. Arunachalam. The late Sambhu Nath De, a cholera investigator based in Calcutta who died in 1985 , was nominated several times for the Nobel Prize by no less than Joshuah Lederberg. However, in his own country, he was not even nominated a fellow of any Indian academy. Presumably, cholera was too close to local preoccupations to qualify as a prestigious topic in India and it was too exotic a topic to form the basis for a "universalistic" Nobel Prize. Sic transit gloria mundi.

34. In the United States and in Europe, an "orphan disease" is a rare disease and this means that it touches fewer than 200,000 people. See http://www.rarediseases.info.nih.gov/asp/diseases/diseases. asp. However, the logic is the same as for the poor countries: The relatively small number of patients does not create a sufficient market to stimulate the interest of pharmaceutical companies. Governments, however, may be moved to doing some research for such diseases.

35. It is interesting to see that a journal specifically devoted to neglected tropical diseases has recently been launched by the Public Library of Science, which is to say in Open Access: http:// www.plosntds.org/home.action.

36. F. Spagnolo, "Brazilian Scientists' Publications and Mainstream Science: Some Policy Implications", Scientometrics 18 (3-4) (1990): 205-218.

37. Tibor Braun and Ildikó Dióspatonyi, “The Counting of Core Journal Gatekeepers as Science Indicators Really Counts. The Scientific Scope of Action and Strength of Nations," Scientometrics 62 (3) (2005): 297-319.

38. Tibor Braun, op. cit. (note 8), p. 109.

39. Manfred Bonitz, op. cit. (note 8). The author simply documents the fact that, in general, citations received stand below the expected level but for a minority of countries, the reverse is true. Coupling Bonitz' observation with Braun's remarks about the distribution of gatekeepers should bring us closer to an etiology of the phenomenon.

40. Abel L. Packer and Rogerio Meneghini, "Learning to Commu- 
nicate Science in Developing Countries," Interciencia 32, no. 9 (September 2007): 643-47. The whole SciELO project now present in about ten countries, including Spain and Portugal in Europe, is a concerted effort to move beyond the obstacles inhibiting the development of autonomous scientific capability in developing countries. See below for more on SciELO.

41. E. Garfield, "Mapping Science in the Third World," Science and Public Policy (June 1983): 112-27, in particular p. 114.

42. This means "failure to earn." It is a calculation that works on hypothetical grounds: Had the following been true, I would have benefited by so much. Given that I did not earn as much, I failed to earn something. This something is the manque à gagner.

43. To write this article, I have had to read a number of articles from the journal Scientometrics. The language of some of the articles is simply atrocious, even to a non-native English speaker like myself, which shows that the editorial input is essentially absent. Likewise, the extremely costly volume cited in note 8 and published by Kluwer incorporates articles written in unacceptable English. In short, the claim for "added value" through editing often appears vacuous not to say more. On this topic, see also http://www.mx2.arl.org/Lists/SPARC-OAForum/ Message/4026.html.

44. See http://www.taxpayeraccess.org/.
45. See http://www.listserver.sigmaxi.org/sc/wa.exe?A2=ind04\&L= american-scientist-open-access-forum \&F=1\&P=72202.

46. See http://www.scielo.org/index.php?lang=en.

47. On the Chinese Science Citation Index, see Loet Leydesdorff and Jin Bihul, "Mapping the Chinese Science Citation Database in Terms of Aggregated Journal-Journal Citation Relations," Journal of the American Society for Information Science and Technology 56, no. 14 (2005): 1469-79.

48. For the "Open Journal System," itself part of the Public Knowledge Project (PKP), see http://pkp.sfu.ca/?q=ojs.

49. See Abel L. Packer, "The SciELO Model for Electronic Publishing and Measuring of Usage and Impact of Latin American and Caribbean Scientific Journals," available in Google Scholar at the following URL: http://www.scholar.google.com/scholar?hl= fr\&client=firefoxa \&rls=com.ubuntu:fr:official $\&$ hs $=6 \mathrm{NV} \&$ q=author: $\% 22$ Packer $\% 22+$ intitle: $\% 22$ The+SciELO+Model+for +electronic+publishing+and+measuring $+\ldots \% 22+\& u m=1 \& i e=$ UTF-8\&oi=scholarr.

50. See http://blogdokura.blogspot.com/ or, for a slightly different presentation, http://kuramoto.wordpress.com/. Helio Kuramoto has been a very active force behind this law. He has organized a petition in favor of this law: http://www.petitiononline.com/ mod_perl/signed.cgi?PL1120. 